\title{
A STATE OF READINESS: AN EXPLORATION OF THE CLIENT'S ROLE IN MEETING AT RELATIONAL DEPTH
}

ROSANNE KNOX is a PhD student at the University of Strathclyde, Glasgow, UK, researching clients' experiences of relational depth in individual counseling. Rosanne is a manager in a UK national telephone counseling service for children and young people, and is a BACP accredited person-centered therapist with a private practice in London.

MICK COOPER is a Professor of Counseling at the University of Strathclyde and a Chartered Counseling Psychologist. Mick is co-author, with Professor Dave Mearns, of Working at relational depth in counselling and psychotherapy (Sage, 2005) and author of Essential Research Findings in Counselling and Psychotherapy: The Facts are Friendly (Sage, 2008), Existential Therapies (Sage, 2003), and a wide range of other texts on person-centred, relational, existential and pluralistic approaches to therapy. Mick lives in Glasgow with his partner and four young children.

\footnotetext{
Abstract

It is widely acknowledged that the therapeutic relationship is important to therapeutic outcome. In recent years there has been additional evidence to suggest that specific, identifiable moments of relational depth between client and therapist can also have a major positive impact on the progress and outcome of therapy; however the question of how such moments occur remains largely unexplored. Are they solely initiated by the therapist, or does the client have a role too? This paper explores clients' perceptions of the factors facilitating an experience of relational depth. Findings suggest that
} 
immediately prior to such an experience the clients themselves have reached a state of readiness, and as making a positive decision to bring their vulnerability to the fore in the therapeutic relationship, thereby facilitating a potential moment of change. Findings are discussed in relation to contemporary theory with implications for practice given.

Keywords: Client's readiness; person-centered; relational depth; qualitative research; therapeutic relationship

The importance of the therapeutic relationship is widely acknowledged, particularly in relation to the therapeutic alliance (Bordin, 1979; 1994; Horvath and Luborski, 1993), with research findings suggesting a correspondence between a strong therapeutic alliance and positive outcome (Hovarth and Bedi, 2002; Krupnick et al, 1996). Increasingly a range of relational aspects within the therapeutic alliance, such therapist relational styles and attitudes, and clients' perceptions of those attitudes, have been explored (Bachelor, 1991; Bachelor and Horvath, 1999; Lambert 1992; Asay and Lambert, 1999). A metaanalysis undertaken by the American Psychological Association Division for Psychotherapy Task Force concluded that the therapy relationship "makes substantial and consistent contributions to psychotherapy outcome independent of the specific type of treatment" (Steering Committee, 2002, p. 441).

The centrality of the quality of the relationship to therapeutic outcomes has been emphasized and conceptualized by different orientations in different ways. From the psychoanalytical perspective, for instance, an important aspect of the relationship is 
highlighted by the Control-Mastery theory, which posits that the client's 'pathogenic' beliefs originate from traumatic experiences (Silberchatz, 2005). The assumption is that clients come to therapy with an unconscious plan to relinquish their unhelpful pathogenic beliefs. The Control-Mastery theory, therefore, would indicate that the most important element of a facilitative therapeutic alliance is the therapist's ability to disconfirm the client's pathogenic beliefs, whether conscious or unconscious. However the strength or facilitative nature of the alliance may not be immediately obvious, as the client's process in disconfirming their pathogenic beliefs will include testing the therapist in a variety of different ways, which on the surface might look like resistance.

Within the existential field, the gestalt therapist Hycner (1991) has drawn on the work of Buber (1970) and Friedman (1985) to develop a dialogical approach with the aim of facilitating a mutual encounter. Within the existential-humanistic field, Bugental (1978) has referred to interpersonal presence in terms of an individual's willingness both to know themselves and to be known by others. Existential-humanistic therapists emphasize the importance of the client's presence and openness to the therapist, and encourage articulation of the 'lived moment' of the therapeutic encounter (Bugental, 1978; May, 1958; Yalom, 2001). Much of the therapeutic work is focused around challenging the client's resistance to openly engage in such an encounter. Combined with this is Bugental's (1978, p.37) notion of therapist 'accessibility', which he describes as "having the intention to allow what happens in a relationship to matter." In this sense, being present requires one not only to verbalize one's own authenticity, but also to be fully open to the authenticity of the other. For existential-humanistic therapists, therefore, the 
willingness of the therapist to be present in the relationship is vital, not only to facilitate the presence of the client, but also to create a sense of safety in which the client can confront her problems and act upon her discoveries (Schneider and May, 1995).

Alongside these developments, Rogers too highlighted the value of 'presence': “...perhaps I am in a slightly altered state of consciousness in the relationship, when whatever I do seems to be full of healing" (Rogers, 1986, p. 137). A study by Geller and Greenberg (2002) into therapists' experiences of presence produced descriptions including feelings of immersion, expansion, grounding and 'being with and for the client'.

Against this backdrop it has been argued within the person-centered field that one of the key relational factors is the 'depth' of therapeutic relating between client and therapist (Mearns and Cooper, 2005; Schmid and Mearns, 2006). This is not just a question of therapist and client being in contact with each other (Whelton and Greenberg, 2001; Rogers, 1957), but of a particular level and quality of contact. Therapy can consist both of periods of gradual, almost indiscernible change, as well as specific moments of intensity and heightened emotion, sometimes where therapist and client are experiencing a profound moment of engagement and connectedness. Such moments are well documented across the spectrum of theoretical approaches, although described and conceptualized differently in accordance with the theoretical viewpoint. Buber's (1970) notion of the 'I-thou' relationship is well known, and within the existential approach Rowan (1998) refers to moments of profound connectedness as 'linking'. In the 
psychoanalytical field Stern speaks of intersubjective moments, or 'moments of meeting' (Stern, 2004) while Ehrenberg (1992) talks of the 'intimate edge'. The value of relating at depth has also been acknowledged by CBT therapists (eg., Grant, Townend \& Mills, 2008).

The notion of 'relational depth' was developed by Mearns (1996), and has been further explored by Mearns and Cooper (2005), Schmid and Mearns (2006), and Mearns and Schmid (2006). Relational depth is defined by Mearns and Cooper as:

"A state of profound contact and engagement between two people, in which each person is fully real with the Other, and able to understand and value the other's experiences at a high level" (2005, p. xii).

With researchers increasingly turning their attention to this area, evidence is now beginning to emerge suggesting that specific, identifiable moments of relational depth between client and therapist can have a major positive impact on the progress and outcome of therapy. In a separate analysis of the present interview data focusing on clients' experiences of specific moments of relational depth (Knox, 2008), all participants could identify one or more moments with at least one therapist which they experienced as a moment of relational depth. Descriptions given included feelings of safety, aliveness, transparency and openness. While the number of specific moments described by each participant was low, indicating a relative rarity of occurrence, those that were identified were felt to be highly significant moments in therapy with an enduring positive effect. These included feeling better, being more connected to self, improved relationships with 
others and an ability to move on and tackle things in their life. A quantitative study by Wiggins (2008) found that around 20\% of events identified by clients as particularly important in therapy can be characterized as moments of relational depth, and in an online study into relational depth by Leung (2009) both client and therapist participants perceived relational depth as being important both for personal change and for therapeutic outcomes.

While empirical evidence of the positive contribution of client-therapist in-depth relating continues to grow, the question of how relational depth is facilitated and sustained remains largely unexplored. In addition, much research has focused primarily on the role of the therapist, often from the perspective of therapists themselves. In recent years, however, researchers and theorists in the humanistic field have been turning their attention, not only to the relationship itself, but also to the client's role in the process of therapy. Rychlak’s (1994) Logical Learning Theory proposes that individuals are intentional and behave with purpose and in accordance with reasons and goals, so that behavior cannot only be understood in term of passive responses. Bohart and Tallman have written of the importance of the client's agency in the therapeutic process, describing the client as the 'primary healing force', and the 'creative agent' (Bohart \& Tallman, 1999, p.23) in the relationship. They suggest that it is the therapist's role to provide a relationship which will enable the client to self heal, a process which continues not just in the therapy session but also outside as they go about their everyday lives. In addition Jordan (1997) has emphasized the value of mutual empathy, highlighting the role and importance of the client's own effectiveness, a concept which has recently been 
the subject of a mutual encounter study by Murphy (2008). Findings of this study indicate that therapeutic outcome improves when mutually high levels of empathy, congruence and unconditional positive regard exist. Moreover Cooper's (2008) overview of therapeutic outcome studies suggests that the most significant factors associated with positive outcome are client variables, over both the relationship and the therapist's skills and attributes. Lambert (1992) has estimated that $40 \%$ of therapeutic improvement can be attributed to client variables including extra-therapeutic events.

Among the first to focus on clients' experiences of in-depth encounter, McMillan and McLeod's (2006) study into clients' experiences of relational depth explored their perceptions of relationships which they felt were facilitative, and those which were felt to be inadequate. A major finding of this study was that clients experienced a sense of 'letting go' in order to fully engage with their therapist in a deep relationship, making a decision to drop their protective stance, sometimes described as taking a leap of faith. Participants also spoke of experiencing a sense of flow with no turning back, with some describing an altered state of awareness. The study also highlighted the clients' internal representation of their therapists, assisting their reflections and processing between sessions, and demonstrated how some clients might be aware from the start whether or not a therapist will be right for them.

Further to the exploration of clients' experiences of specific moments of relational depth (Knox, 2008), this paper covers a separate analysis of the data from that study which addresses the question of what makes relational depth possible. Is it simply what the 
therapist brings to the relationship, or does the client additionally play a role? Here clients' perceptions of the processes and events which led up to an experience of relational depth with their therapist are given.

\section{METHOD}

\section{Procedure}

The research, undertaken by the first author, took the form of a qualitative interview study (Kvale, 1996), being a phenomenological exploration (McLeod, 2001; Moustakas, 1994) of clients' experiences of relational depth. Interviews were semi-structured using a person-centered approach. An interview guide was used to ensure that all pre-considered areas for exploration were covered, while still leaving as much scope as possible to facilitate an in-depth exploration of participants' experiences and perceptions. Prior to the interview participants were given an information sheet which included an abbreviated version of Mearns and Cooper's (2005) definition of a specific moment of relational depth:

'A moment of profound contact and engagement in which each person is fully real with the Other' (2005, p.xii).

Participants were told that this was an initial guide only, and that their own experiences might be very different.

Initially participants were asked if they could describe any experience from their own therapy which they would describe as a moment of relational depth. However in 
answering this question, most participants also contextualized their experiences within a therapeutic journey, including previous experiences of therapy, their own processing following those relationships, and the moments leading up to, and immediately prior to the specific events described.

Two participants also went on to describe moments of relational depth with their supervisors, descriptions which bore striking similarities to those described with therapists. While there is clearly some cross over between the two settings, it is acknowledged that further research would be needed to distinguish more accurately between experiences of relational depth in therapy and supervision settings. The data relating to these descriptions have not been used for this analysis. Ethical approval was granted by the University of Strathclyde Ethics Committee.

\section{Participants}

All participants were therapists or trainee therapists who had themselves been clients of individual counseling. It was felt that this client group might have the language and ability to give detailed descriptions of their own experiencing. Their therapeutic language might also help with the process of categorization. In addition it was felt that this client group would be experienced in managing any difficult emotions should they arise as a result of taking part in this study. However it is acknowledged that there are clearly limitations in using this client group and a useful next step would be a similar study with non-therapist clients. It is worth noting that some participants had not yet entered therapist training at the time of the experiences they were describing, although their 
subsequent learning will undoubtedly have affected their language and perceptions of the events being recalled.

This study focused solely on the phenomenological experiencing of clients, and therefore the joint openness or mutuality of experiencing as suggested by the notion of relational depth can only be viewed from the client's perspective. An interpersonal process recall study into the synchrony of experiencing by both parties, involving both client and therapist participants, is currently being undertaken (Abbate, cited by Cooper, 2009).

Participants consisted of 5 men and 9 women living in different parts of England, with ages ranging from twenties to sixties. Ethnicities were described as: Asian $(n=2)$, African-Asian $(\mathrm{n}=1), 1$ Afro-Caribbean $(\mathrm{n}=1)$, Swiss-Italian $(\mathrm{n}=1)$, Australian $(\mathrm{n}=1)$, White British $(\mathrm{n}=8)$. They were recruited by advertising in journals, putting up flyers in counseling settings, giving talks to groups and the researcher's own network. All had been clients of predominately person-centered therapy.

\section{The Authors}

As humanistic therapists, we believe that the primary agent of therapeutic change is the client's capacity for active self-healing (Bohart and Tallman, 1999). However, the extent to which moments of in-depth connection contribute to this process is one that intrigues us. Recent research regarding clients' experiences of relational depth (McMillan and McLeod, 2006), has also led us to wonder about the role of the client, as well as the therapist, in making such a meeting possible. 


\section{Analysis}

All interviews were tape-recorded and transcribed verbatim by the first author, and transcripts were sent to participants for checking. Using a grounded theory approach (Strauss and Corbin, 1998) the data were broken down into domains and sub-domains, and meaning units were identified from the first three transcripts. These were coded in relation to the emergent substantive categories involving several stages of refinement, checking and re-coding. This process was then applied to the remaining transcripts. As the mapping of categories was refined new levels of categories and sub-categories evolved. The analysis was then audited by the second author resulting in further levels of categorization and fine tuning of the analysis.

In order to describe the weighting of categories in terms of the number of participants contributing to each category, Rodgers and Cooper's (2006) scoring scheme for qualitative thematic analysis has been used (see www.strathclydecounselling.com). Terms used include 'all' (14), 'nearly all' (12-13), 'most' (9-11), 'around half' (7-8), 'some' (3-6) and 'a couple' (2). Categories receiving only one response have been omitted.

\section{FINDINGS}

The data were organized into two domains as follows:

The client's historical process: following previous experiences of therapy The client's in-session processing: in the moments leading up to an experience of relational depth 
Table: Clients' perceptions of their role in meeting at relational depth

Learning from previous experience of therapy

Working through feelings of difficulty

(No. of participants)

Realized what I didn't want: coldness/blankness/distance

Realized what I wanted: closeness/openness/depth/understanding

Gained some understanding of counseling process/approaches

Made more considered choice of therapist

Wanted some matching with self

Felt more comfortable/safer with (gender/setting)

Chose by approach/reputation

Therapist seemed more genuine

\section{Client's in-session processing}

\section{CLIENT'S PERCEPTIONS/EXPERIENCING}

$\begin{array}{ll}\text { Perceived change in therapist } & 12 *\end{array}$

Therapist different with me: more honest/open to me $\quad 7$

$\begin{array}{ll}\text { Therapist inviting me in } & 7\end{array}$

$\begin{array}{ll}\text { Therapist challenged me } & 6\end{array}$

Change in own experiencing of therapist 11 *

Felt Safer with therapist/trusted therapist 5

$\begin{array}{ll}\text { Aware of therapist's understanding/acceptance } & 10\end{array}$

Felt that core conditions really meant/felt really cared for 6

Realized that therapist isn't perfect/is /human 3

Change in relationship

Both sharing feelings/co-reflexivity/mirrored 4

Built up to point where could take to a deeper level 3

\section{CLIENT'S READINESS}

$\begin{array}{ll}\text { Client's desire/preparedness } & 11 \text { * }\end{array}$

Own desire/need/willingness/choice/readiness 10

Had developed own ability to relate at depth $\quad 5$

Heightened emotions in the moment 9*

In distress/fear/confusion/ vulnerable 5

$\begin{array}{ll}\text { Aware of/ in touch with difficult/deeper emotions } & 6\end{array}$

$\begin{array}{ll}\text { Own decision/action } & 10 \text { * }\end{array}$

$\begin{array}{ll}\text { Took a risk } & 10\end{array}$

Made a decision (to open up/go deeper/let therapist in $\quad 7$

Let it happen/no going back/let go 3 


\section{PRECIPITATING EVENT}

Occurrence of external traumatic event 4

Impending ending of relationship 3

\section{SPONTANEOUS}

Occurred spontaneously following own decision

* No. of participants contributing to category

\section{THE CLIENT'S HISTORICAL PROCESS}

Most participants related their own process towards a moment of meeting at relational depth back to one or more previous experiences of therapy where they felt there had been no relational depth. These relationships ranged in length from a couple of sessions to a few months. There was no significant difference in the process described for the different durations of therapy relationships. The initial phase was one of ongoing processing after the relationships had ended, beginning with a period of working through feelings of difficulty that remained. One participant spoke of the process she went through when her therapist suddenly and unexpectedly ended the relationship, initially throwing the participant into confusion and despair:

"I remember walking out of the room and just wanting to cry, and I remember I went home and just cried and cried and cried. So that relationship ended... I just like, counseling's rubbish, you know, if people can do that."

As time went on the same participant described taking more control, leading to her being a more pro-active participant in the creation of a new therapeutic relationship:

"Over the days that followed that, I started to pull myself together. I learnt from that to be responsible for my own feelings... and, um, I learnt some self responsibility as well. What I did learn from it, in the couple of weeks after that, was what not to do... 
I would make sure everything was very clear, the boundaries are very clear, from the start. So I did learn an awful lot from that."

Such experiences led participants to realize what they did and did not want from therapy, initiating a reflection on their own relational styles, and their specific needs in relation to the difficulties they were experiencing in their lives. Talking of a previous experience which was also felt to be inadequate, another participant said:

"You might as well talk to a white sheet of paper, but then, you're not, you're talking to a person, but that person isn't offering you anything back. But I think that's because my preference is not to work like that. My preference is not to be seen by somebody like that. So, for other people, I believe that could be OK."

Most spoke of a desire for closeness, openness and deeper understanding. Some realized their wish for greater intimacy within the therapeutic relationship: “... it made me feel there's more to me than just my problems... I would like to bring myself here as well as just my problems. I think also was the need for the intimacy... intimate contact with somebody else, um, which I think for me is particularly strong."

Around half also talked of the positive effects of gaining some understanding of the counseling process, and of the different counseling approaches. This helped them both in terms of understanding their own role in the therapeutic process, and in informing their next choice of therapist. Indeed, in order to find what they now knew they wanted, nine described taking more control by going on to make a more considered choice of therapist. Around half 
chose a therapist whom they felt displayed some similarities to themselves, for example in terms of personality, culture, age or political beliefs. One participant expressed the importance of the therapist's voice:

“Something about the accent perhaps, I don't know. It was kind of an auditory thing I guess now thinking about it, I most certainly would not have opened up if she'd spoken in a way that would have made me think she was living a different life."

A couple chose therapists who displayed characteristics that they themselves aspired to. One said:

"So I needed to find someone who was in touch with my... with... with who I am."

A few looked for a therapist with whom they simply felt more comfortable, for example a woman, or someone they were paying as opposed to a volunteer, or working in an environment that suited the participant. Around half selected by approach or reputation, or by recommendation from a trusted friend or colleague. One highlighted the reassuring combination of a recommendation reinforced by the immediate feeling that this therapist was right for him:

"And within, the first time I met him, I just thought, yes, this feels right. And that was... he was recommended to me by someone that I trusted. His way of relating was similar to the way I relate." 


\section{THE CLIENT'S IN-SESSION PROCESSING}

\section{Client's perceptions/experiencing}

In the moments immediately prior to an experience of relational depth some participants perceived a change in their therapist, feeling that they were in some way being different from how they had been previously. This was expressed in a variety of ways, for example more real, showing more emotion, reacting differently, or as experiencing the participant differently. One participant said:

"How I experienced her way of being totally changed, because before that I was thinking am I actually getting anything from being here, um, maybe she's too purist for me... that I was aware that she was hearing me, maybe before I just twittered on, and didn't feel like she was hearing me."

Most felt that their therapist was more open to them in terms of sharing their own feelings with the participant, or more clearly conveying their empathy, acceptance and a deeper level of care. Another said:

"It's kind of... I'm making sense of why it changed there... was, that, yeah, the core conditions were there, but they were meant. I really felt that they were meant. I really felt that she was there, and understood what I meant, and how I felt."

Around half felt that their own ability or willingness to relate at a deeper level was awakened by the therapist's invitation. For some this was experienced as their therapist being more focused or serious in their desire to understand and connect, and some became aware that they were being given the opportunity, sometimes highlighted by the 
fact that the therapist had slowed the pace or was making it possible for the participant to go slower. A few felt that their therapist had taken a risk or made a challenge, often unusually within in the relationship. One participant described the effect this had on her:

"So I responded. When I think about it now, I slowed down. When I think about it now there was something definitely happened then. It wasn't just the words. It wasn't just the way she looked at me. There was something that she... really understood how I felt, and the depth that left me with."

Most participants also felt that their own experiencing of their therapist changed, irrespective of whether their therapist was actually being different. Around half described feeling safer within the relationship, having gradually built up trust. Most described becoming aware of their therapist's understanding and acceptance, with some emphasizing the genuine care they felt from their therapist. Others felt a change in the relationship itself, having built up to a point where closer engagement felt possible, as in the following example:

"If she's really in tune with me, then she'll know me, and therefore she'll be able to challenge me in the right way to make me work. And we can unfold whatever might be there. And I think that's happening, just happening, after a year."

Another said:

"Yeah, so we'd got to that point where we could relate. He could... I felt he had some understanding of where I was coming from. And I certainly had an understanding of where he was coming from. I had to know who he was, it had to be two way for me." 
Some felt that there was a perceived shift in the level of openness between them, often very subtle and difficult to describe:

"I really, by her presence, I guess, and maybe she just experienced me differently that day. It was almost indiscernible that changed... but it felt very tangible... so something on a very subtle level... ethereal almost."

\section{The client's readiness}

Most participants felt that a contributing factor to the occurrence of a moment of relational depth was their own readiness or willingness at that time. Some participants spoke of their own desire and preparedness to enter into a relationship at a level of relational depth in terms of where they were on their own journey of self development. One participant described the sense that her previous experiences of therapy which she had found difficult were all part of the journey bringing her to a point of being able to engage with the therapist with whom she experienced relational depth:

"I suppose for me, I met my therapist at the time when I thought, OK, I've had enough now, I can't carry on, in my sort of head space, I've got to do something about it. But also I needed to see these other people before I got to this person as well. So it was a bit of a journey. Yes, exactly [I was ready to meet her]. That's when the engagement was really solid." 
During the course of the interview one participant began to look at the different levels of relating which she experienced in two separate therapeutic relationships in the context of her own self development:

"But maybe it's difficult because now, I'm so much on, that is it now that I'm expecting that [relational depth], but really at that time it was fine? I don't think I could have done this level of thinking then."

In the moments immediately prior to the described experience of relational depth, most participants were experiencing a heightened level of emotion, including fear, distress, confusion or feeling highly vulnerable. For some those feelings seemed new or related to a recent event, while others were connecting to painful or difficult feelings which had long been hidden.

Most felt it was their own decision to take the relationship to another level, as one participant described it:

"I'd got to a point where I wanted to know more. I wanted to grow, I wanted to take a risk, I suppose. Yes, yes. I... I do believe that the... the risk element, me taking that risk has helped me move on further." Most participants also attributed their experience of relational depth to their own action as opposed to that of the therapist. Some felt that they had taken the risk themselves, most described making a decision, either to go deeper, to open up, to relate more closely or to let the therapist in, as one participant put it: 
"I think it was actually, um, the way... maybe because I was more open, too. Perhaps I'd come to the point of being more open. I was saying what I needed from her, and being honest, I think that opened a way for her, because she was different with me.”

At this point participants also described feeling ready to be vulnerable, and willing and able to open up, both to their innermost feelings, and to the therapist. Some spoke of the sensation of just letting it happen, describing it as a flow with its own momentum:

"And it was as if... as if it was flowing... as there was a flow... almost like a stream, a river, that, I'd opened... I'd opened a gate that allowed the emotions to actually come out rather than me feel them inside. Allowed them to be expressed."

Some expressed the feeling that, having taken the first step, there was no turning back:

"But it was a very definite thing within myself, that happened, that I allowed myself to be so open, and let my defenses down enough, and it was almost as if, I'd got to the point, even though I was reluctant, I got to the point of no return and I thought, I'm going to go for it. I got to a point where I was speaking where I thought, yeah, I'm going to do it, I can't go back, and I spoke very openly.”

\section{Precipitating event}

For some participants the described experience of relational depth was precipitated by a traumatic event in their lives which acted as a catalyst for taking the relationship to a deeper level. For example one participant was distressed by seeing a significant person in her life outside the counseling room, and another had just heard that a close friend was 
terminally ill. For a few it was the impending end of the relationship which led to the experience of relational depth, with both client and therapist finding the ability to reach a new level of authenticity.

\section{Spontaneous}

A couple spoke of the spontaneous nature of the experience, but only after the decision had been made:

"But once I'd decided that I was going to speak and touch on things that were so deep and intimate, it was... it just happened, it wasn't something I was controlling, it was spontaneous."

\section{DISCUSSION}

Participants' descriptions of being aware of their own desire or readiness to make a decision to open up to the therapist corresponds to McMillan and McLeod's (2006) study which found that clients experienced a willingness to 'let go' following a decision to enter into a relationally deep relationship. In both studies participants described a sense of flow like a stream or a river, or opening a gate, with the sense of passing the point of no return. Although the participants of McMillan and McLeod's study were referring to the relationship in general while participants of this study were talking about specific moments of relational depth, the similarities of these descriptions are striking. Indeed most participants of this study felt that the decision was their own, and that they were the pro-active agent in relating more deeply. This strongly supports Bohart and Tallman's (1999) view of the client as an agentic, active self healer, and a parallel might also be 
drawn with the concept of clients coming to therapy with a plan to have their pathogenic beliefs disconfirmed, as described by the Control-Mastery theory (Silberchatz, 2005).

Clients who were experiencing a heightened level of emotion at what might be described as the apex of the moment of relational depth, seemed not only to be aware of their own vulnerability, but also willing to be vulnerable, and feeling ready to do so. In this sense it could be argued that they felt less vulnerable, as any perceived potential threat was reduced or eliminated by their increased awareness of the therapist's provision of the core conditions to a high degree. At this point participants described making a decision to open up to their therapist, connect with their own feelings and allow their emotions to come out. This would perhaps also lend some understanding to Wiggins' (2008) factor analysis of data from 343 relational depth questionnaires with items created using the findings of Knox (2008) and workshops facilitated by Cooper, in which the factor entitled 'vulnerability', although present, appeared surprisingly weak. This finding might also correspond to the proposition of Bohart and Tallman (1999) that change is more likely to occur if a client is process focused rather than outcome focused. Indeed on talking about their experiences, participants appeared to have strong, vivid memories of their own processing at the time, and of their own role as a pro-active agent in the deeper exploration of self that the experience facilitated. The specific issue that they were addressing at times seemed less significant than the process of coming to a point where they were able to address it. 
It has sometimes been suggested that such moments of intense meeting happen spontaneously, as was a finding of Cooper's (2005) study into therapist's experiences of relational depth; yet while a couple of participants did speak of a spontaneous quality, they also said that the event itself was initiated by their own decision. It is possible therefore that this difference in emphasis is due to the experience of spontaneity being predominately that of the therapist, while the client maintains a greater sense of control over the event. We feel this is an area for further exploration. Perhaps this finding also highlights the need for therapists to be open to such experiences when they arise, rather than be aiming for such an experience with clients. However it is also worth noting that in the moments prior to an experience of relational depth participants reported sensing an invitation from their therapist, either to go deeper within themselves, or to relate more closely to the therapist, corresponding to Mearns and Schmid's (2006) emphasis on the importance of inviting clients, not making them feel obligated to relate at depth.

Most participants also indicated that their own process towards the moment described originated some considerable time before the event itself, often to previous experiences of therapy. Following an experience of an unsatisfactory therapeutic relationship participants described developing a greater understanding about what it was they wanted or did not want from a therapeutic relationship. Participants reported taking a more active role at the point of selection of their subsequent therapist, by consciously discriminating between therapists and looking for a specific type of person or therapeutic approach. Again this would correspond to McMillan and McLeod's (2006) findings which indicated that the client might make an assessment about whether or not they will be able to enter a 
facilitative relationship with a particular therapist at the very beginning of the relationship. These findings have clear implications for the way in which counseling organizations allocate clients to therapists, and the level of input clients have in this process.

There appeared to be no significant age, ethnicity or gender differences in participants' responses within the different categories, either in their processing and reflections following previous experiences of therapy, or in their experiencing in the moment immediately prior to the described moment of relational depth. However it is possible that these aspects might not have been highlighted due to the small sample. It is also acknowledged that as all the described experiences are from the client's perspective, further studies would be needed to explore more fully the mutuality or synchrony of experiencing.

Overall, this study highlights the role of the client as a proactive participant in the therapeutic process, with the client's own process and ultimately readiness crucial factors which should not be overlooked. Discussing Rogers' sixth condition involving the client's perception, Whelton and Greenberg (2001) have highlighted the fact that due to inevitable subjective interpretation, perception at least to some extent determines reality, therefore to what extent a client might perceive the provision of empathy and unconditional positive regard will depend on their own attention, awareness and historical learning experiences, all of which constitute a moving process. Whether the moments of relational depth described were precipitated by an actual change in the therapist's way of 
being with the client, or a change in the client's perception of the therapist, or indeed by the client's heightened level of emotion, or by an external event, from the client's point of view the moment itself was initiated by themselves. Having reached a point of readiness, it was the client who made the decision to meet the therapist at relational depth.

The second of Rogers' conditions which he stated were necessary and sufficient for therapy to take place proposes that the client is "in a state of incongruence, being vulnerable or anxious" (Rogers, 1957, p.221). While the first condition implies a willingness on the part of the client to enter into some level of relationship with the therapist, and indeed condition six requires some level of perception of the client of being in receipt of those conditions, the finding of this study would suggest that, prior to entering into a deeply facilitative relationship involving meeting the therapist at a level of relational depth, the client is also in a state of readiness.

In his relationship inventory, Barrett-Lennard (1986) separated out the two aspects of unconditionality and prizing in the condition of unconditional positive regard. This study would seem to suggest that the point at which clients become aware of, and trust in the therapist's empathy, congruence, and in particular the unconditionality of the therapist's positive regard, is the point at which they become ready to make a decision to bring their vulnerability to the fore, open up to their own deepest feelings in the company of the therapist, and meet at relational depth. 


\section{REFERENCES}

Asay, T. P. and Lambert, M. J. (1999). The empirical case for the common factors in therapy: Quantitative findings. In M A. Hubble, B. L. Duncan and S. D. Millar, (Eds.), The heart and soul of change: What works in therapy (pp. 23-55). Washington DC: American Psychological Association.

Bachelor, A. (1991). Comparison and relationship to outcome of diverse dimensions of the helping alliance as seen by client and therapist. Psychotherapy: Theory, Research and Practice, 28, 534-549.

Bachelor, A. and Horvath, A. O. (1999). The therapeutic relationship. In M. A. Hubble, B. A. Duncan, and S. D. Millar (Eds.), The heart and soul of change: What works in therapy (pp. 133-178). Washington: American Psychological Association.

Barrett-Lennard, G. T. (1986). The relationship inventory now: Issues and advances in theory, method and use. In L. S. Greenberg and W. M. Pinsof (Eds.), The psychotherapeutic process: A research handbook (pp. 439-476). New York: Guilford Press.

Bohart, A. C. and Tallman, K. (1999). How clients make therapy work. The process of active self-healing. Washington: American Psychological Association.

Bordin, E. S. (1979). The generalizability of the psychoanalytic concept of the working alliance. Psychotherapy: Theory, Research, Practice, Training, 16(3), 252-260.

Bordin, E. S. (1994). Theory and research on the therapeutic working alliance: New directions. In A. O. Horvath and L. S. Greenberg (Eds.), The working alliance: Theory, research and practice (pp. 13-37). New York: Wiley. 
Buber, M. (1970). I and thou New York: Scribner's Sons.

Bugental, J. (1978). Psychotherapy and process. New York: McGraw-Hill.

Cooper, M. (2005). Therapists' experiences of relational depth: A qualitative interview study. Counselling and Psychotherapy Research, 5(2), 87-95.

Cooper, M. (2008). Essential research findings in counselling and psychotherapy: The facts are friendly. London: Sage Publications

Cooper, M. (2009). Relational depth: Where we are now. Presentation given at the $2^{\text {nd }}$ relational depth conference: Relational depth: Current theory and practice, University of Nottingham, $1^{\text {st }}$ July, 2009.

Ehrenberg, D. (1992). The intimate edge. Extending the reach of psychoanalytic interaction.: New York and London: W.W. Norton.

Friedman, M. (1985) The healing dialogue in psychotherapy. New York: Jason Aronson.

Geller, S. M. and Greenberg, L. S. (2002). Therapeutic presence: Therapists' experiences of presence in the psychotherapy encounter. Person-Centered and Experiential Psychotherapies, 1, 71-86.

Grant, A., Townend, M. and Mills, J. (2008). Assessment and case formulation in cognitive behavioural therapy. London: Sage Publications.

Horvath, A. O. and Bedi, R. P. (2002). The alliance. In J. C. Norcross (Ed.), Psychotherapy relationships that work: Therapist contributions and responsiveness to patients (pp. 37-69). New York: Oxford University Press.

Horvath, A. O. and Luborski, L. (1993). The role of the therapeutic alliance in psychotherapy. Journal of Consulting and Clinical Psychology, 61, 561-573. 
Hycner, R. (1991). Between person and person: Towards a dialogical psychotherapy. Highland, NY: Gestalt Journal Press.

Jordan, J. V. (1997). Relational development through mutual empathy. In A. Bohart and L. S. Greenberg (Eds.), Empathy reconsidered: New directions in psychotherapy (pp. 343-452). Washington DC: American Psychological Association.

Knox, R. (2008). Clients' experiences of relational depth in person-centred counselling. Counselling and Psychotherapy Research, 8(3), 182-188.

Krupnick, J. L., Sotsky, S. M., Simmens, S., Moyer, I., Elkin, I. and Watkins, J. (1996). The role of the therapeutic alliance in psychotherapy and pharmacotherapy outcome: Findings in the National Institute of Mental Health treatment of depression collaborative research program. Journal of Consulting and Clinical Psychology, 64(3), 532-539.

Kvale, S. (1996). Interviews: An introduction to qualitative research interviewing. London: Sage Publications.

Lambert, M. J. (1992). Implications for outcome research for psychotherapy integration. In J. R. Norcross and M. R. Goldstein (Eds.), Handbook of psychotherapy integration (pp. 94-129). New York: Basic Books.

Leung, J. (2009). A quantitative online study exploring the factors associated with the experience and perceived importance of relational depth. Dissertation submitted. Glasgow: University of Strathclyde.

May, R. (1958). Contributions of existential psychotherapy. In R. May, E. Angel and H.

F. Ellenberger (Eds.), The psychology of existence: An integrative, clinical perspective. New York: McGraw-Hill. 
Mearns, D. (1996). Contact at relational depth. Counselling, 7, 306-311.

Mearns, D. and Cooper, M. (2005). Working at relational depth in counselling and psychotherapy. London: Sage Publications.

Mearns, D. and Schmid, P. F. (2006). Being-with and being-counter: Relational depth:

The challenge of fully meeting the client. Person-Centered and Experiential Psychotherapies, 5(4) 255-265.

McLeod, J. (2001). Qualitative research in counselling. London: Sage Publications.

McMillan, M. and McLeod, J. (2006). Letting go: The client's experiences of relational depth. Person-Centered and Experiential Psychotherapies, 5(4) 277-292.

Moustakas, C. (1994). Phenomenological research methods. London: Sage Publications.

Murphy, D. (2008). Counselling and Psychotherapy: A mutual encounter. Retrieved $5^{\text {th }}$ January 2009 from:

www.strath.ac.uk/Departments/counsunit/docs/res_rd D_Murphy pres.pdf.

Rodgers, B. and Cooper, M. (2006). Proposed scoring scheme for qualitative thematic analysis. Retrieved $1^{\text {st }}$ September 2007 from: $\underline{\text { www.strath.ac.uk/Departments/counsunit/features/articles.html }}$

Rogers, C. R. (1957). The necessary and sufficient conditions of therapeutic personality change. In H. Kirschenbaum and V. Henderson (1990) (Eds.), The Carl Rogers Reader (pp. 219-235). London: Constable.

Rogers, C. R. (1986). A client-centered/person-centered approach to therapy. In H. Kirschenbaum and V. Henderson (1990) (Eds.), The Carl Rogers Reader (pp. 135152). London: Constable. 
Rowan, J. (1998). Linking: Its place in therapy. International Journal of Psychotherapy, $3(3), 245-54$.

Rychlak, J. F. (1994). Logical learning theory. Lincoln, NE: University of Nebraska Press.

Schmid, P. F. and Mearns, D. (2006). Being-with and being-counter: Person-centered psychotherapy as an in-depth co-creative process of personalization. Person-Centered and Experiential Psychotherapies, 5(3), 174-190.

Schneider, K. J. and May, R. (1995). Guidelines for an existential-integrative (EI) approach. In K. J. Schneider \& R. May (Eds.), The Psychology of existence: An integrative, clinical perspective. New York: McGraw-Hill Inc.

Silberschatz, G. (2005). Transformative relationships: The Control-Mastery theory of psychotherapy. New York: Routledge.

Steering Committee (2002). Empirically supported therapy relationships: Conclusions and recommendations on the Division 29 Task Force. In J. C. Norcross, (Ed.), Empirically supported therapy relationships: Psychotherapy relationships that work. Therapist contributions and responsiveness to patients (pp. 441-3). New York: Oxford University Press.

Stern, D. N. (2004). The present moment in psychotherapy and everyday life. New York: W. W. Norton \& Company.

Strauss, A and Corbin, J. (1998). Basics of qualitative research: Techniques and procedures for developing grounded theory $\left(2^{\text {nd }}\right.$ ed.). Thousand Oaks: Sage.

Whelton, W. J. and Greenberg, L. S (2001). Psychological contact and perception as dialogical construction. In P. Sanders and G. Wyatt (Eds.), Rogers' Therapeutic 
conditions: Evolution, theory and practice. Volume 4: Contact and Perception. RossOn-Wye: PCCS Books.

Wiggins, S. (2008). Development of a measure to assess relational depth. Retrieved $1^{\text {st }}$ March 2008 from: www.strath.ac.uk/Departments/counsunit/docs/res_rd_S_Wiggins_pres.pdf.

Yalom, I. (2001). The gift of therapy: Reflections of being a therapist. London: Piatkus. 